\title{
THE ULTIMATE BEHAVIOUR OF CRACKED SQUARE HOLLOW SECTION T-JOINTS
}

\author{
S.T. Lie ${ }^{*}$, Z.M. Yang, S.P. Chiew and C.K. Lee \\ School of Civil and Environmental Engineering, Nanyang Technological University \\ 50 Nanyang Avenue, Singapore 639798, Singapore \\ Tel: +65-6790-5284; Fax: +65-6792-1650 \\ *(Corresponding author: E-mail address: cstlie@ntu.edu.sg)
}

Received: 28 October 2006; Revised: 20 May 2006; Accepted: 22 May 2006

\begin{abstract}
The ultimate static strength of tubular joints is usually calculated at the design stage based on empirical formulae incorporating the joint geometry, loading mode and materials strength. However, fatigue cracks have been detected in some aging structures, which tend to reduce the static strength. Methods for predicting the loss of strength of cracked tubular joints are therefore very important in practice. Very few published results are available concerning the residual strength of cracked square hollow section (SHS) joints. In order to develop guidelines on assessing the static strength of fatigue-cracked square hollow section (SHS) joints, a range of numerical analysis and full-scale test has been carried out on cracked and uncracked T-joints. The non-linear elastic-plastic finite element (FE) technique has been employed successfully for calculating the plastic collapse loads of uncracked and cracked T-joints under axial load at the brace end. Accordingly, an approach to predict the ultimate strength of cracked SHS T-joints is proposed in this paper. The experimental test results, conducted at room temperature, have confirmed and agreed well with the FE analysis findings.
\end{abstract}

Keywords: crack; finite element technique; non-linear analysis; square hollow section (SHS); T-joints; ultimate strength

\section{INTRODUCTION}

It is well known in practice that almost all engineering structures and components contain cracks or crack-like flaws. These are either introduced during manufacture, especially if welding is used, or during the earlier service life by environment fatigue loading or by accidental damage, i.e. impact and earthquake. When the defect size increases, the structure strength capacity is reduced accordingly, and therefore, there is a need to develop a reliable procedure to determine the residual static strength of such structures containing defects.

The fracture mechanics method is the most reliable approach to assess the integrity of a cracked or damaged component with crack-like defects. The most widespread and successful assessment approach is the failure assessment diagram (FAD) approach. Based on this approach, API RP579[4], BS7910 [5] and R6 [13] give guidance for assessing the acceptability of defects in welded structures. This approach was originally developed from two criteria assessment proposed by Dowling and Townley [9]. It enables the integrity of cracked components to be assessed through two separate calculations based on the two extremes of fracture behaviour, linear elastic and fully plastic. A design curve is used to interpolate between these two failure criteria. The relative position of the assessment point on the diagram, derived from the two separate calculations, determines the integrity of the structure as shown in Fig. 1. If the assessment point falls inside the failure curve, the structure is deemed safe; if the assessment point is on or outside the curve, then failure is predicted to occur. An increased load or larger crack size will move the assessment point along the loading path toward the failure line. The reliability of the method depends on how accurately the intersection zone is described by the failure assessment curve which in turn depends on the structural geometry, type of loading and crack size. 
Although the existing codes and standards do provide guidance in the form of detailed procedures for the fracture assessments, these are intended for general applications and do not necessarily give optimal solutions for all types of structures, such as welded SHS tubular joints. Because of the complexity of these tubular joint geometries, there are uncertainties with essential fracture parameter solutions; and both experimental and numerical studies are costly. In this paper, the formulae of plastic collapse load of cracked square hollow section (SHS) T-joints is derived in accordance with the yield line theory, and the failure assessment curve (FAD) is constructed using the $J$-integral approach. Compared with the standard BS7910 [5] FAD, some recommendations are given to extend the utilization of the standard FAD.

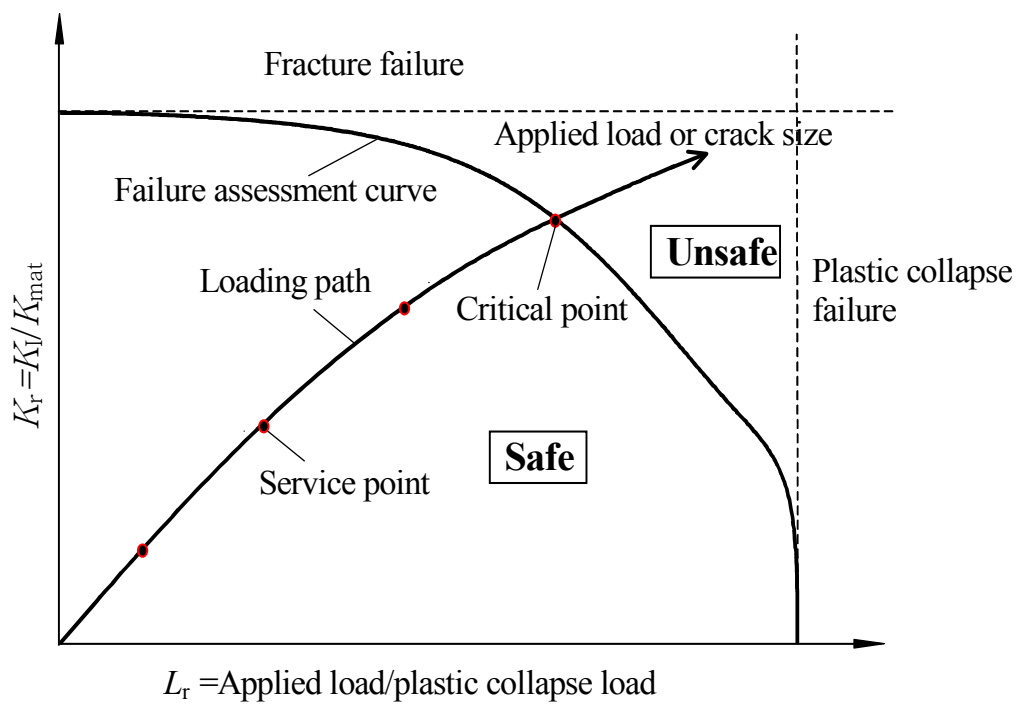

Figure 1. FAD Philosophy for the Assessment of Flawed Structure

\section{DETERMINATION OF PLASTIC COLLAPSE LOAD}

The plastic collapse loads for the cracked geometry are evaluated by reducing the plastic collapse loads for the corresponding uncracked geometry (Cheatani and Burdekin [6]). When the brace to chord width ratio $\beta$ is less than 0.8 , normally the failure model of the $\mathrm{T}$ and Y-joints under brace end axial loads is chord face yielding (Wardenier [14]). The ultimate strength of uncracked RHS T and Y-joints can be derived using the yield line pattern as shown in Fig. 2 (Wardenier [14]). Based on the yield line theory, an approach was given to predict the collapse loads of RHS T-joints with surface cracks in this paper, and it is validated numerically.
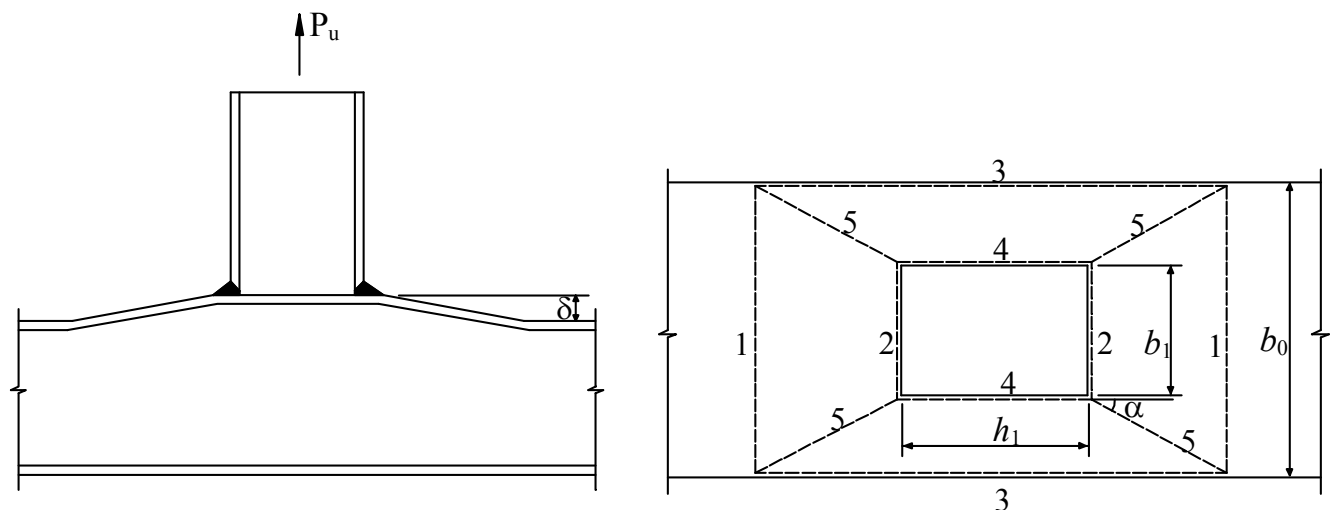

Figure 2. Yield Line Pattern for the Uncracked T-joint 
For the joints containing a surface crack, the ligament in front of the crack has the capability to pull and deform the chord face. Therefore, the axial displacement of the chord face around the entire circumference of the brace and chord intersection can be assumed to be $\delta$ as shown in Fig. 3. Based on the yield line theory, the following two assumptions are deduced,

- The yield line pattern remains the same as the uncracked joint.

- The thickness of the crack region is $t_{0}-a$, where $t_{0}$ is the thickness of the chord face, and $a$ is the vertical depth of the crack under weld toe.

The corresponding yield line pattern for the cracked joint is shown in Fig. 3, the energy participated in the yield lines 1 to 5 keeps the same as the uncracked joint, they $\operatorname{are} \frac{4 \operatorname{tg} \alpha}{1-\beta} \cdot \delta \cdot \mathrm{m}_{\mathrm{p}}$, $\frac{2 \beta \cdot \operatorname{tg} \alpha}{1-\beta} \cdot \delta \cdot \mathrm{m}_{\mathrm{p}}, \quad\left\{\frac{4 \eta}{1-\beta}+4 \operatorname{cotg} \alpha\right\} \cdot \delta \cdot \mathrm{m}_{\mathrm{p}}, \frac{2 \eta}{1-\beta} \cdot \delta \cdot \mathrm{m}_{\mathrm{p}}$ and $4(\operatorname{tg} \alpha+\operatorname{cotg} \alpha) \cdot \delta \cdot \mathrm{m}_{\mathrm{p}} \quad$ respectively.

Because of the influence of the crack, the energy participated in yield line $2^{\prime}$ and $4^{\prime}$ is derived as follow:

yield line $2^{\prime}: \quad\left(b_{1}-l_{\mathrm{c} 1}\right) \cdot \frac{2 \delta}{\left(b_{0}-b_{1}\right) \operatorname{cotg} \alpha} \cdot \mathrm{m}_{\mathrm{p}}+l_{\mathrm{c} 1} \cdot \frac{2 \delta}{\left(b_{0}-b_{1}\right) \operatorname{cotg} \alpha} \cdot \mathrm{m}_{\mathrm{p}}^{\prime}$

yield line $4^{\prime}: \quad\left(h_{1}-l_{\mathrm{c} 2}\right) \cdot \frac{2 \delta}{b_{0}-b_{1}} \cdot \mathrm{m}_{\mathrm{p}}+l_{\mathrm{c} 2} \cdot \frac{2 \delta}{b_{0}-b_{1}} \cdot \mathrm{m}_{\mathrm{p}}^{\prime}$

where $\mathrm{m}_{\mathrm{p}}=\frac{\sigma_{\mathrm{e} 0} \cdot t_{0}^{2}}{4}, \quad \mathrm{~m}_{\mathrm{p}}^{\prime}=\frac{\sigma_{\mathrm{e} 0} \cdot\left(t_{0}-a\right)^{2}}{4}$, and $\sigma_{\mathrm{e} 0}$ is yield strength of the material.

The energy by the external load $P_{\mathrm{u}}$ is equal to the participated energy in the yield lines, which gives $P_{\mathrm{u}}=\frac{2 \sigma_{\mathrm{e} 0} \cdot t_{0}^{2}}{1-\beta}\left\{\operatorname{tg} \alpha+\frac{1-\beta}{\operatorname{tg} \alpha}+\eta\right\}-\frac{\sigma_{\mathrm{e} 0} \cdot\left[t_{0}^{2}-\left(t_{0}-a\right)^{2}\right]}{2} \cdot\left\{\frac{l_{\mathrm{c} 1}}{\left(b_{0}-b_{1}\right) \operatorname{cotg} \alpha}+\frac{l_{\mathrm{c} 2}}{b_{0}-b_{1}}\right\}$

In accordance with assumption 1, the following relationship can be obtained from the uncracked joint (Wardenier, 1982), $\operatorname{tg} \alpha=\sqrt{1-\beta}$.

Substituting Equation (4) into Equation (3) gives the yield load

$$
P_{\mathrm{u}}=\frac{\sigma_{\mathrm{e} 0} \cdot t_{0}^{2}}{1-\beta}\{2 \eta+4 \sqrt{1-\beta}\}-\frac{\sigma_{\mathrm{e} 0} \cdot\left[t_{0}^{2}-\left(t_{0}-a\right)^{2}\right]}{2\left(b_{0}-b_{1}\right)} \cdot\left\{l_{\mathrm{c} 1} \cdot \sqrt{1-\beta}+l_{\mathrm{c} 2}\right\}
$$

where the first term is the yield load of uncracked joint, and the second one is the reduction of the yield load because of the introduction of the crack. If there are several cracks, the additional reduction terms which have the same expression need to be calculated for different crack depths and lengths. Then Equation (5) becomes

$$
P_{\mathrm{u}}=\frac{\sigma_{\mathrm{e} 0} \cdot t_{0}^{2}}{1-\beta}\{2 \eta+4 \sqrt{1-\beta}\}-\sum_{n} \frac{\sigma_{\mathrm{e} 0} \cdot\left[t_{0}^{2}-\left(t_{0}-a^{n}\right)^{2}\right]}{2\left(b_{0}-b_{1}\right)} \cdot\left\{l_{\mathrm{c} 1}^{n} \cdot \sqrt{1-\beta}+l_{\mathrm{c} 2}^{n}\right\}
$$

where $n$ represent the number of cracks. Considering the influence of the weld and the chord wall thickness, the brace to chord width ratio $\beta$ should be $\frac{b_{1}+2 t_{\mathrm{w}}}{b_{0}-2 t_{0}}$, and the bracing member depth to chord width ratio $\eta$ should be $\frac{h_{1}+2 t_{\mathrm{w}}}{b_{0}-2 t_{0}}$ (Wardenier, 1982), where $t_{\mathrm{w}}$ is the width of the weld toe as shown in Fig. 4. 


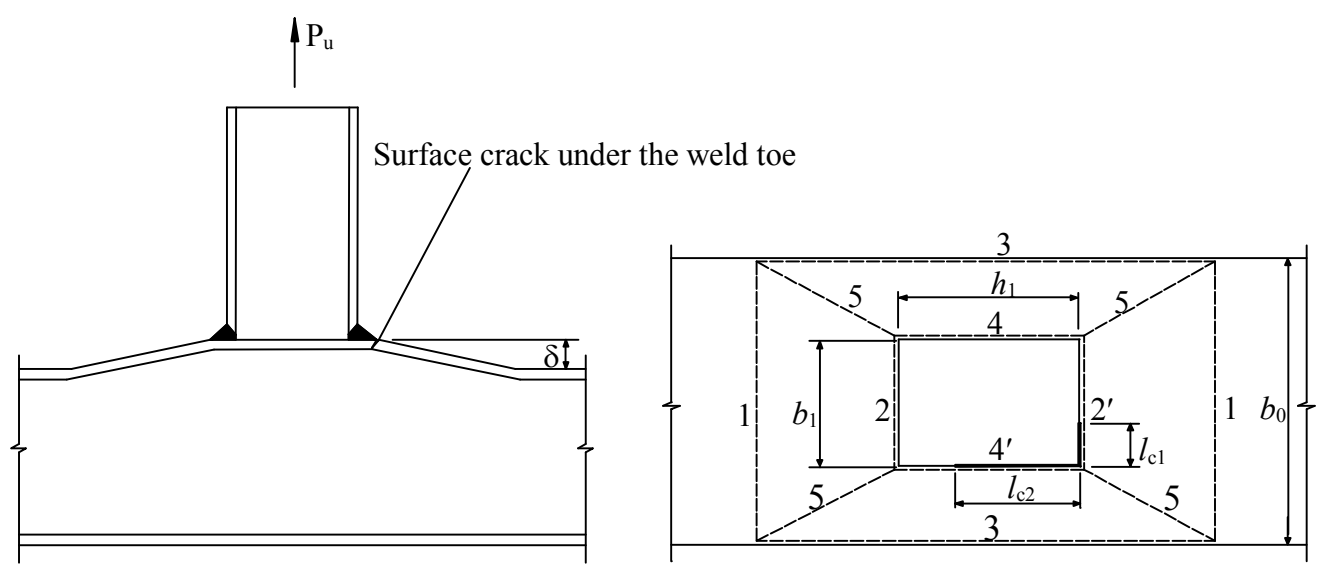

Figure 3. Yield Line Pattern for the Cracked T-joint

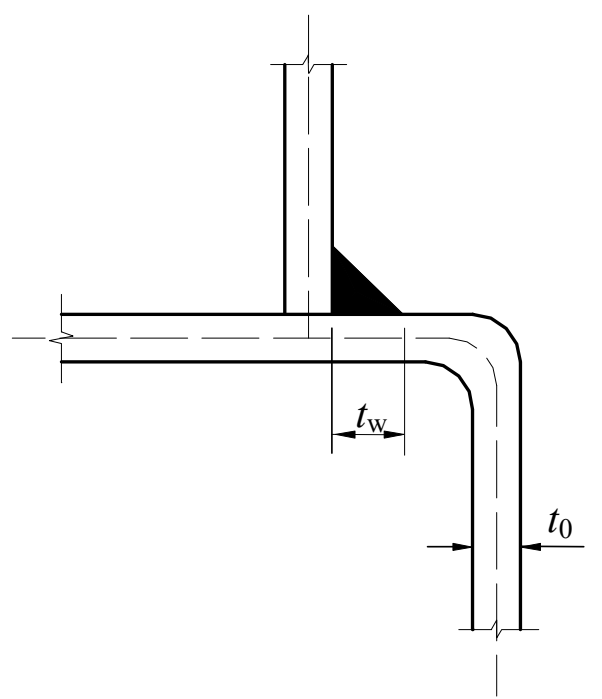

Figure 4. The Weld Details for the RHS T-joints

\section{NUMERICAL MODELING OF CRACKED SHS JOINT}

In accordance with the experimental results (Chiew et al. [7]), the fatigue crack under the weld toe is inclined and slightly curved, and the crack is located at the corner of the brace where the hot spot stress is the highest. Therefore, the crack surface is modelled as an inclined plane which has an angle $\theta$ with the vertical plane as shown in Fig. 5. The crack is located at the inclined crack surface, and the inclined angle $\theta$ is varying with the crack depth. Because the geometry and the stress distribution are not symmetric with respect to the corner, the shape of the crack is not symmetric either. In this study a two halves of semi-ellipse model is used and it is mapped onto the three dimensional inclined crack surface as shown in Fig. 6. 20-node brick elements are used throughout to model the joint except at the crack zone. Around the crack front, the brick elements are degenerated into wedges as shown in Fig. 7. Between the crack front and the field far away from it, 15-node prism elements and 10-node tetrahedron elements are used to refine the mesh gradually. The completed mesh of the cracked SHS T-joint is illustrated in Fig. 8. The mesh close to the crack zone is refined to capture the steep stress gradient.

In elastic problems, the nodes at the crack tip are normally tied together, and the mid-side nodes are moved to the $1 / 4$ points as shown in Fig. 9(a). Such a modification results in a $1 / \sqrt{r}$ strain singularity in the element, which enhances numerical accuracy (Lapidus and Pinder [11]). When a 
plastic zone forms, the $1 / \sqrt{\mathrm{r}}$ singularity does not exist any longer at the crack tip. Consequently, elastic singular elements are not appropriate for elastic-plastic analyses. Fig. 9(b) shows an element that exhibits the desired strain singularity under fully plastic conditions. The element is degenerated to a wedge as before, but the crack tip nodes are untied and the location of the mid-side nodes is unchanged. This element geometry produces a $1 / \mathrm{r}$ strain singularity, which corresponds to the actual crack tip strain field for fully plastic materials (Aliabadi and Rooke [2]).
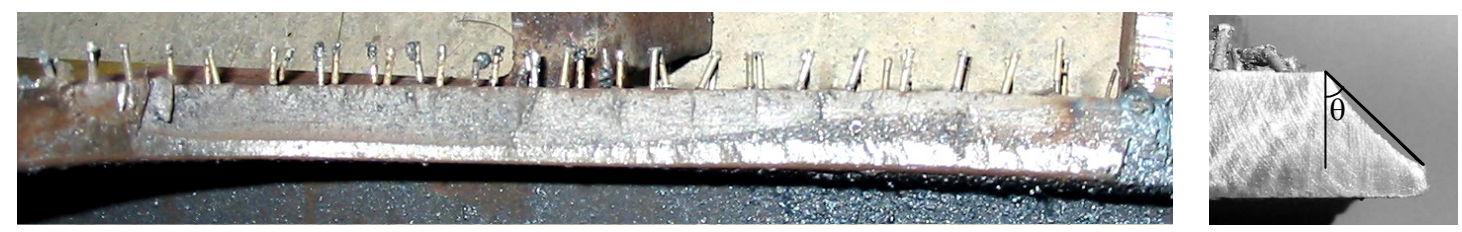

Figure 5. A Typical Crack Surface of the Damaged T-joint

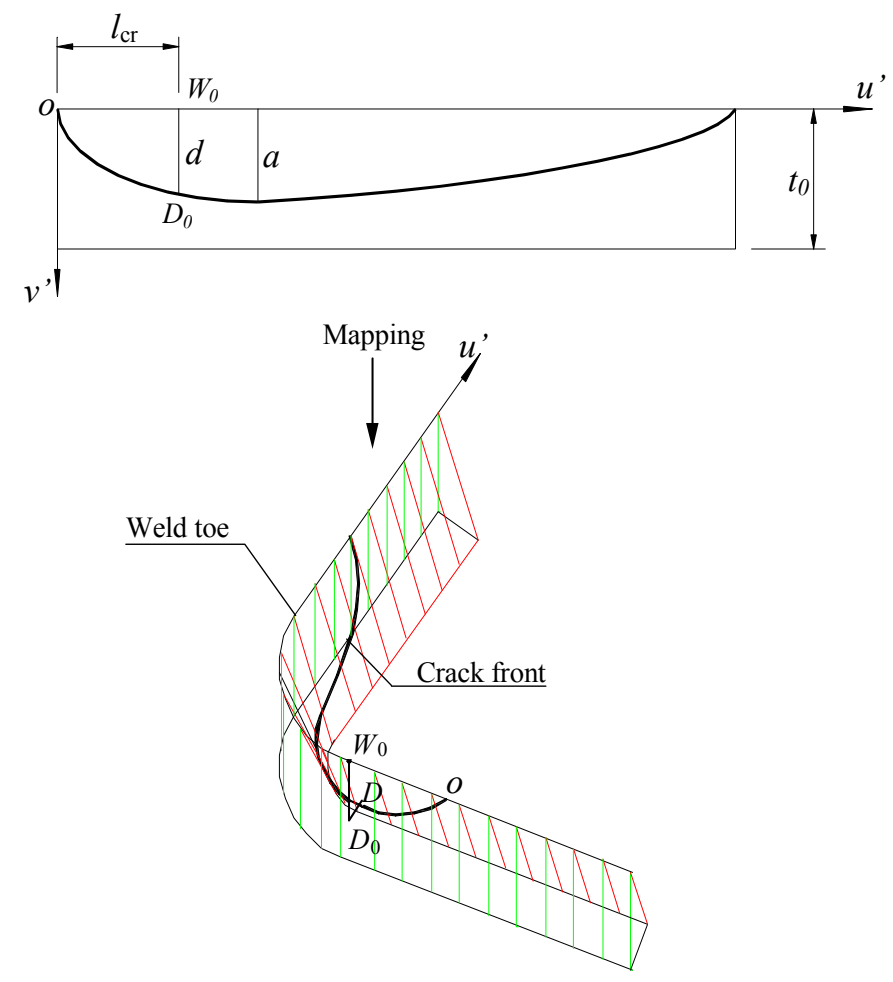

Figure 6. Modelling of the Surface Crack under the Weld Toe

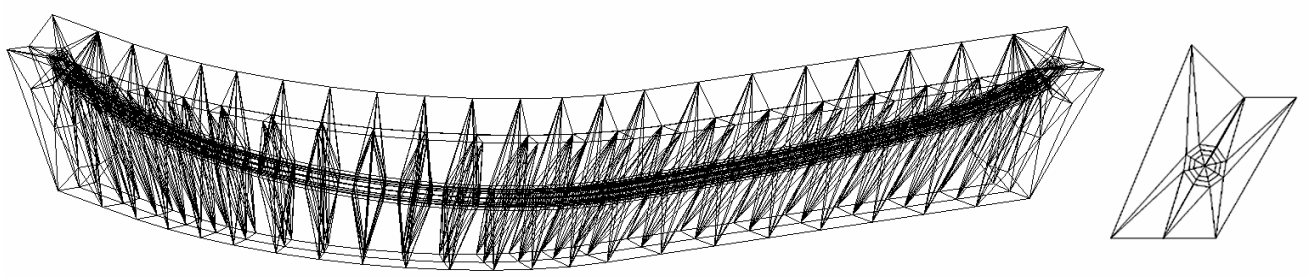

Figure 7. Mesh of the Crack Zone 


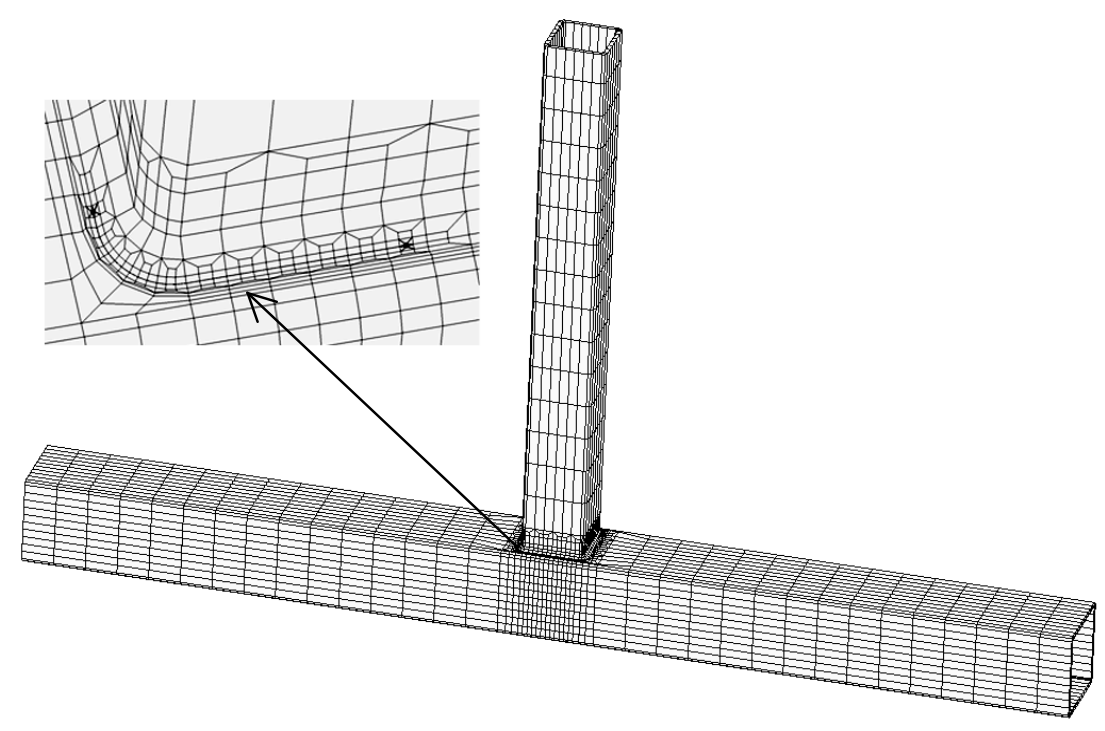

Figure 8. Mesh of the T-joint with Crack

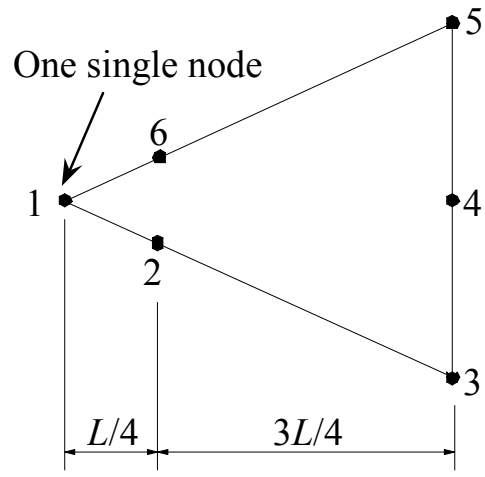

(a) Elastic singularity element

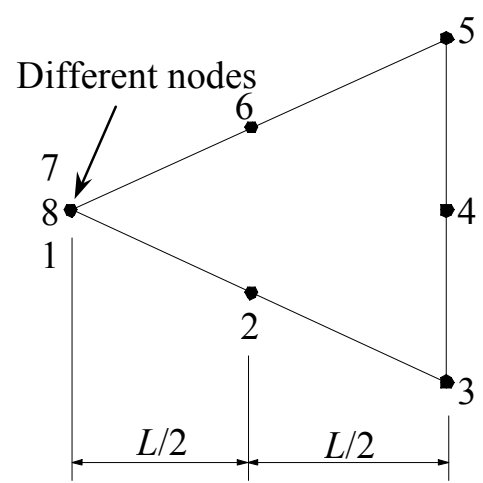

(b) Plastic singularity element

Figure 9. Crack Tip Elements used for Elastic and Elastic-plastic Analyses

\section{STATIC STRENGTH TEST OF CRACKED SHS JOINT}

For validation of the numerical model, two static tests of the cracked T-joints are performed up to failure. A specially designed test rig as shown in Fig. 10 was used to test these SHS T-joints. The specimens were available from the previous fatigue test programmes conducted on a structural steel BS4360-50D. Every specimen contains at least one fatigue surface crack under the weld toe. The dimensions of the joints are given in Table 1, and the weld and crack details are tabulated in Table 2. The weld profile and the specimen preparation were carried out in accordance with the American Welding Society (AWS) Structure Welding Code D1.1-2000 [3] specifications and they were checked using the ultrasonic technique to deem the welds quality. The two ends of the chord were supported on two rollers placed on the top of the concrete supports as shown in Fig. 11. The joint was loaded under displacement control in the test rig with regular pauses for photography, visual examination and instrumentation checks until the load was observed to start decreasing from the maximum value. The applied load was obtained via load cell of the actuators, and it was also measured using the strain gauges attached at the middle of the brace to confirm the load readings. 
The crack growth was monitored using the Alternating Current Potential Drop (ACPD) technique (Dover et al., 1995). The ACPD probes around the fatigue crack location are shown in Fig. 12.

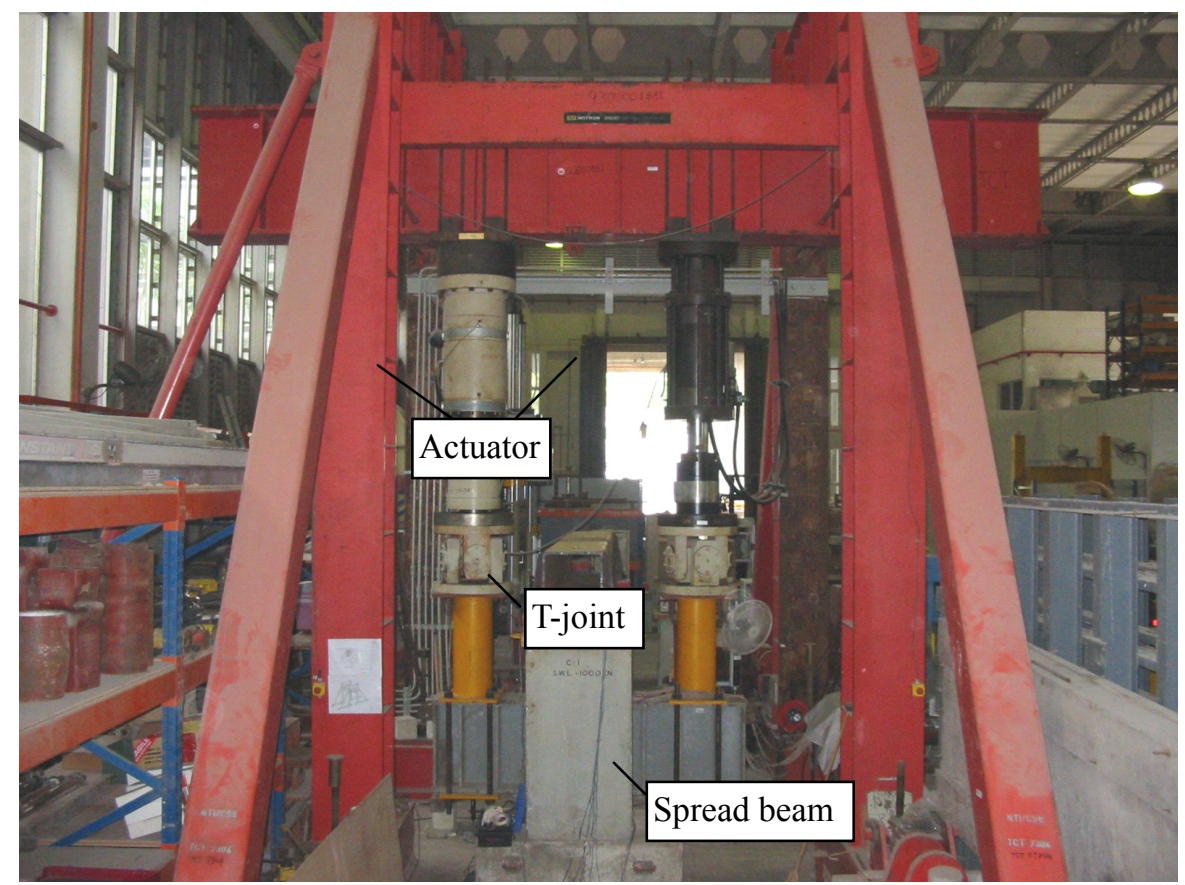

Figure 10. The Test Rig

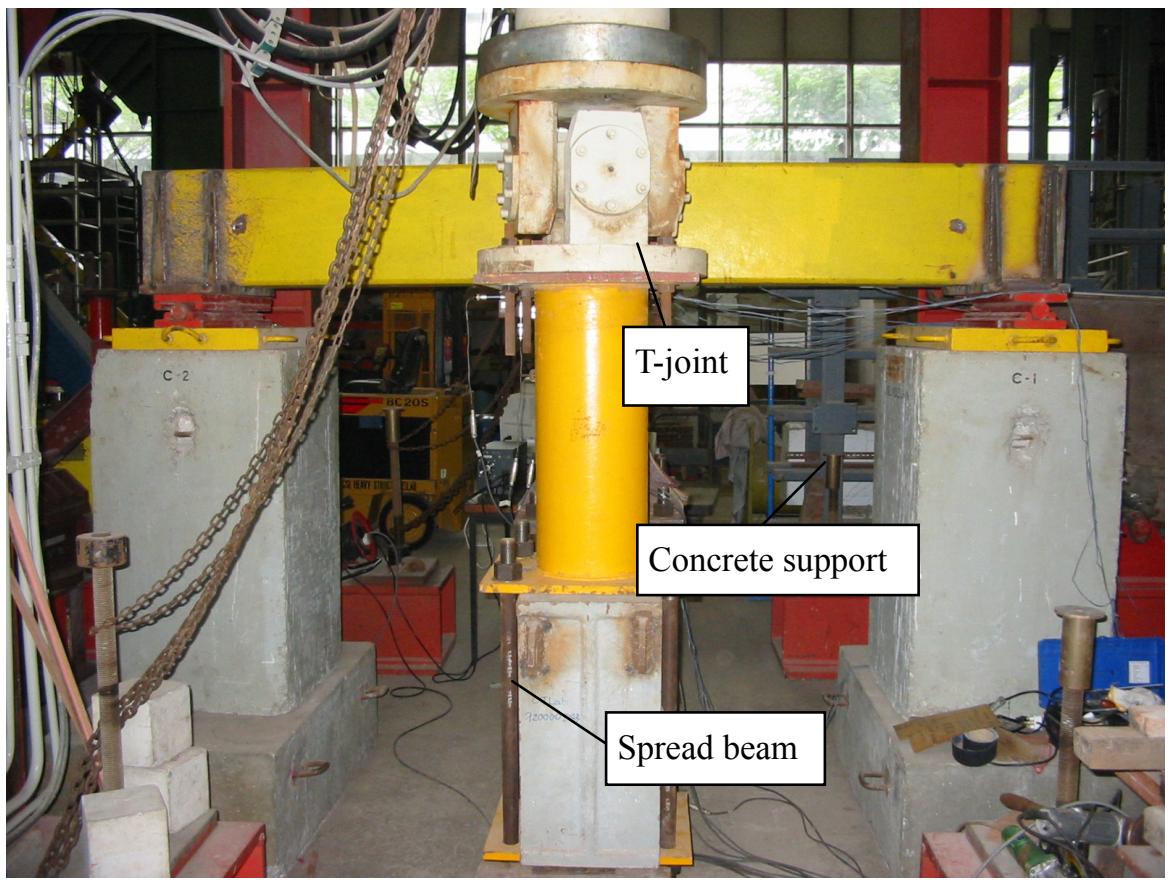

Figure 11. The Static Test Set-up 


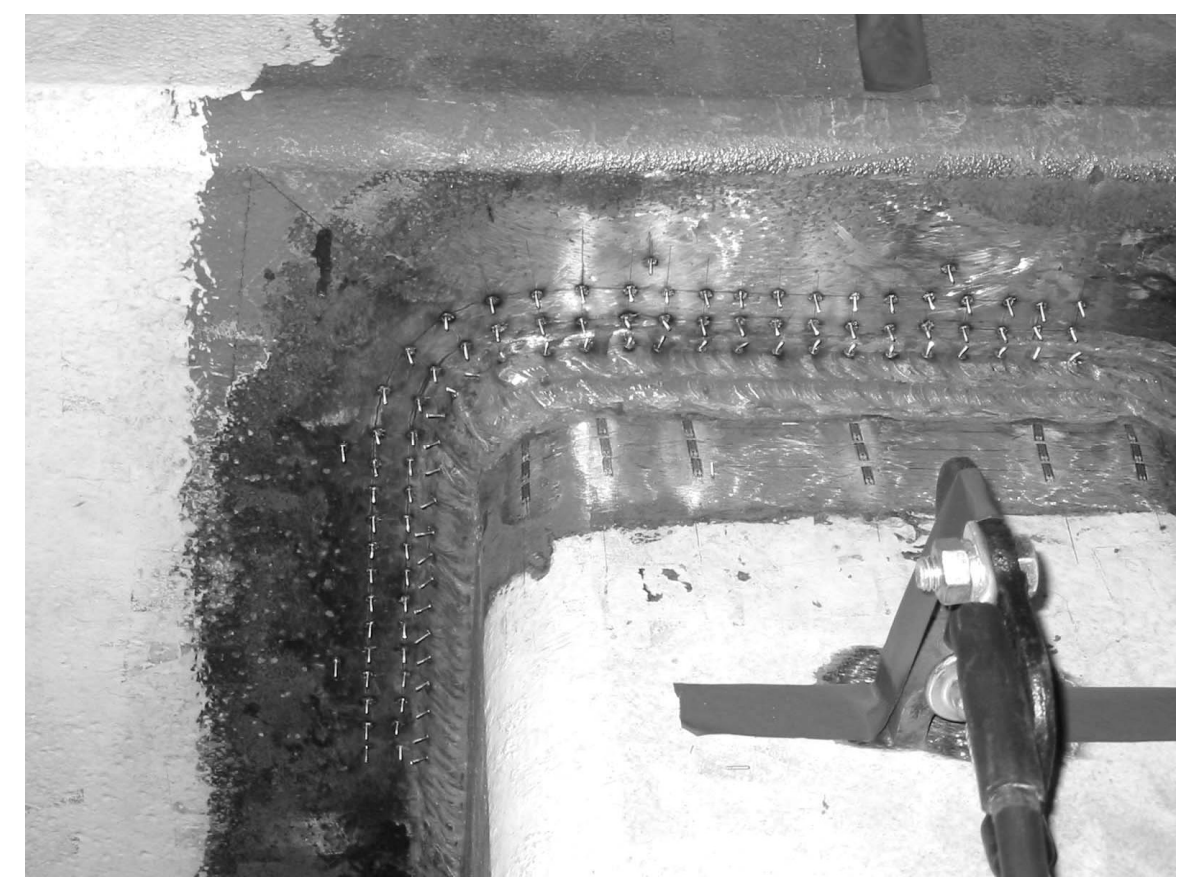

Figure 12. The Set-up of the ACPD Probes

Table 1. Dimensions of the Specimens

\begin{tabular}{|c|c|c|c|c|c|c|}
\hline Specimen & $b_{0}(\mathrm{~mm})$ & $H_{0}(\mathrm{~mm})$ & $t_{0}(\mathrm{~mm})$ & $b_{1}(\mathrm{~mm})$ & $h_{1}(\mathrm{~mm})$ & $t_{1}(\mathrm{~mm})$ \\
\hline $\mathrm{T} 1$ & 350 & 350 & 15 & 200 & 200 & 16 \\
\hline $\mathrm{T} 2$ & 350 & 350 & 15 & 200 & 200 & 12 \\
\hline
\end{tabular}

Table 2. The weld and fatigue crack details

\begin{tabular}{|c|c|c|c|c|c|}
\hline Specimen & $\begin{array}{c}\text { No. of } \\
\text { cracks }\end{array}$ & $\begin{array}{c}L_{\mathrm{c} 1} \\
(\mathrm{~mm})\end{array}$ & $\begin{array}{c}L_{\mathrm{c} 2} \\
(\mathrm{~mm})\end{array}$ & $\begin{array}{c}\text { Crack depth } a \\
(\mathrm{~mm})\end{array}$ & $\begin{array}{c}\text { Weld thickness } t_{\mathrm{w}} \\
(\mathrm{mm})\end{array}$ \\
\hline \multirow{2}{*}{$\mathrm{T} 1$} & 1 & 67 & 217 & 12.7 & 12 \\
\cline { 2 - 5 } & 2 & 47 & 92 & 9.0 & \\
\hline $\mathrm{T} 2$ & 1 & 77 & 187 & 13.6 & 12 \\
\hline
\end{tabular}

Three LVDTs with a stroke capacity of $10 \mathrm{~mm}$ were used to measure the crack mouth opening displacement (CMOD) as shown in Fig. 13. One block and one bracket were attached to the chord face and brace face, and in turn three LVDTs were fixed to the bracket. The three LVDTs are in contact with the block so that the vertical displacement of point 1 and 2 and the horizontal displacement of point 3 relative to the brace can be measured accordingly. If the region between the crack and the measured point is treated as a rigid body, the displacements at the measured points are caused by the displacements and rotations of the crack faces. If the displacement measured by LVDTs 1,2 and 3 are expressed as $d_{1}, d_{2}$ and $l$, the following relationships can be found for the calculation of CMOD,

$\delta_{\mathrm{CMOD}}=\sqrt{d_{\mathrm{c}}^{2}+l_{\mathrm{c}}^{2}}$

$l_{\mathrm{c}}=l-\gamma \cdot h$

$d_{\mathrm{c}}=d_{1}-\gamma \cdot L_{1}$

where the rotation angle of the crack face can be calculated as

$\gamma=\frac{d_{2}-d_{1}}{L_{2}}$ 


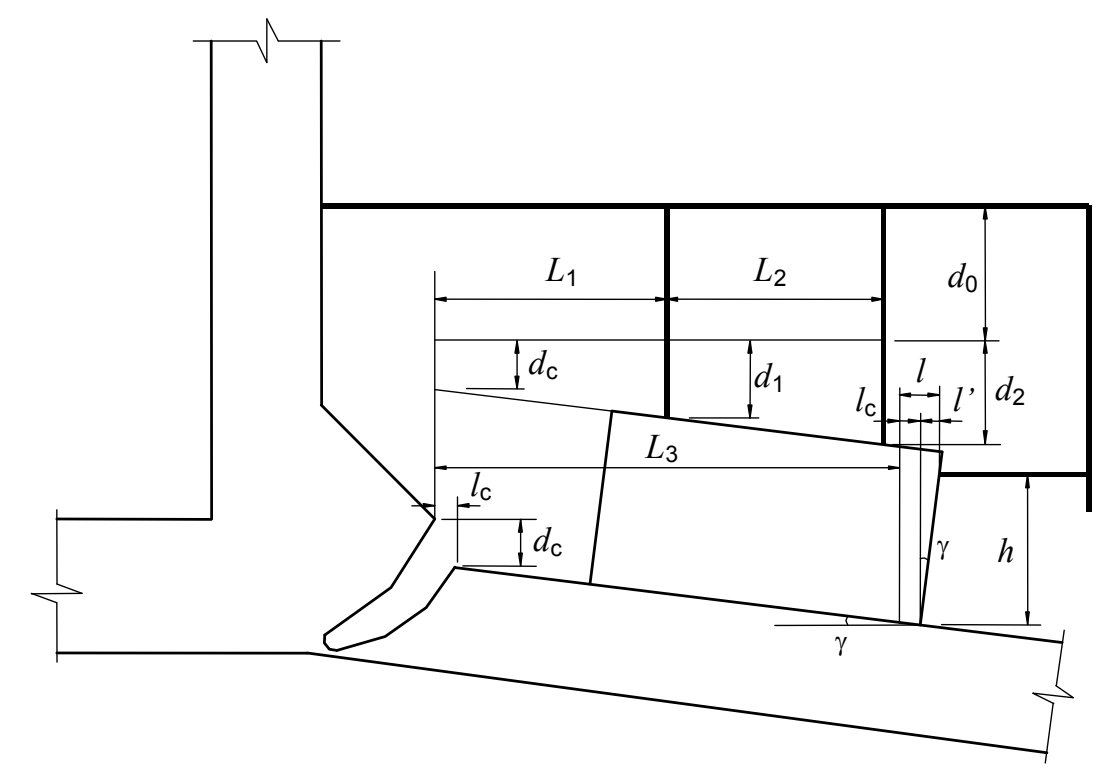

Figure 13. Measurement of the Crack Mouth Opening Displacement

\section{COMPARISONS OF EXPERIMENTAL AND NUMERICAL RESULTS}

Two elastic-plastic analyses are carried out on the T-joints under brace end axial loads using the ABAQUS (2002) finite element program. The dimensions of the joints and cracks are the same as those of specimens T1 and T2. Based on the proposed numerical model of the cracked RHS T-joints, the cracks are modelled using the actual crack dimensions measured from the damaged specimens as shown in Fig. 14.
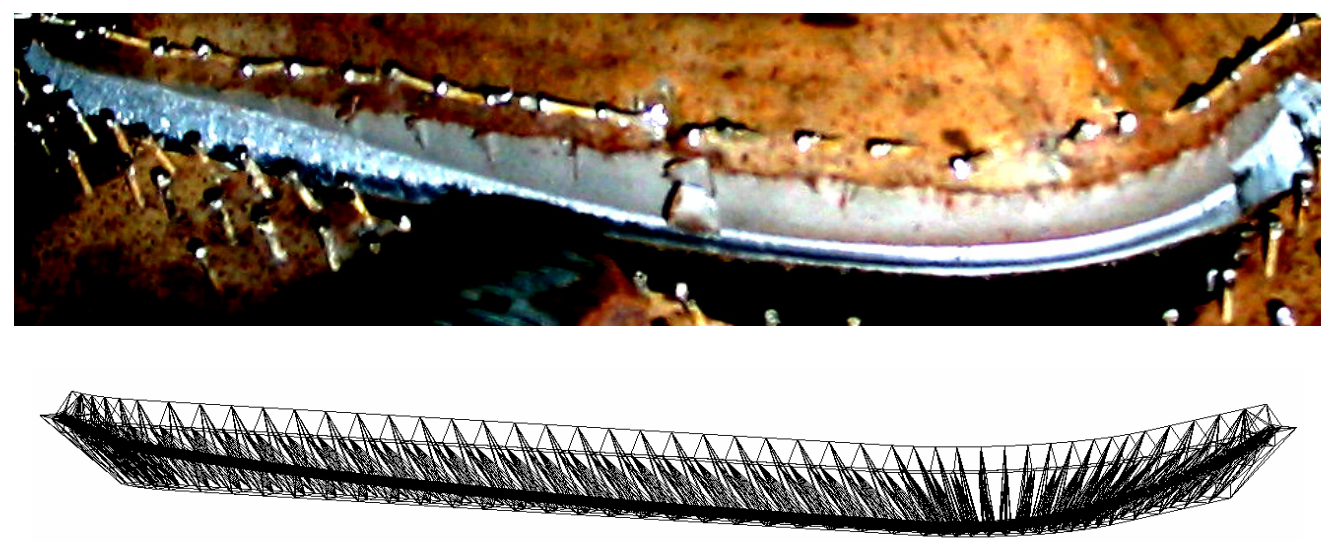

Figure 14. The Mesh of the Crack Compared with the True Crack

6 coupons were cut from the specimens and tested using the Instron 4486 universal testing machine. In accordance with the coupon tests results shown in Fig. 15, the true stress-strain curve was then obtained. In the analyses by ABAQUS [1], a piecewise multi-linear stress-strain curve approximated from the true stress-strain curve is adopted as shown in Fig. 16. The Von-Mises yield criterion and isotropic strain hardening were assumed in this analysis. 


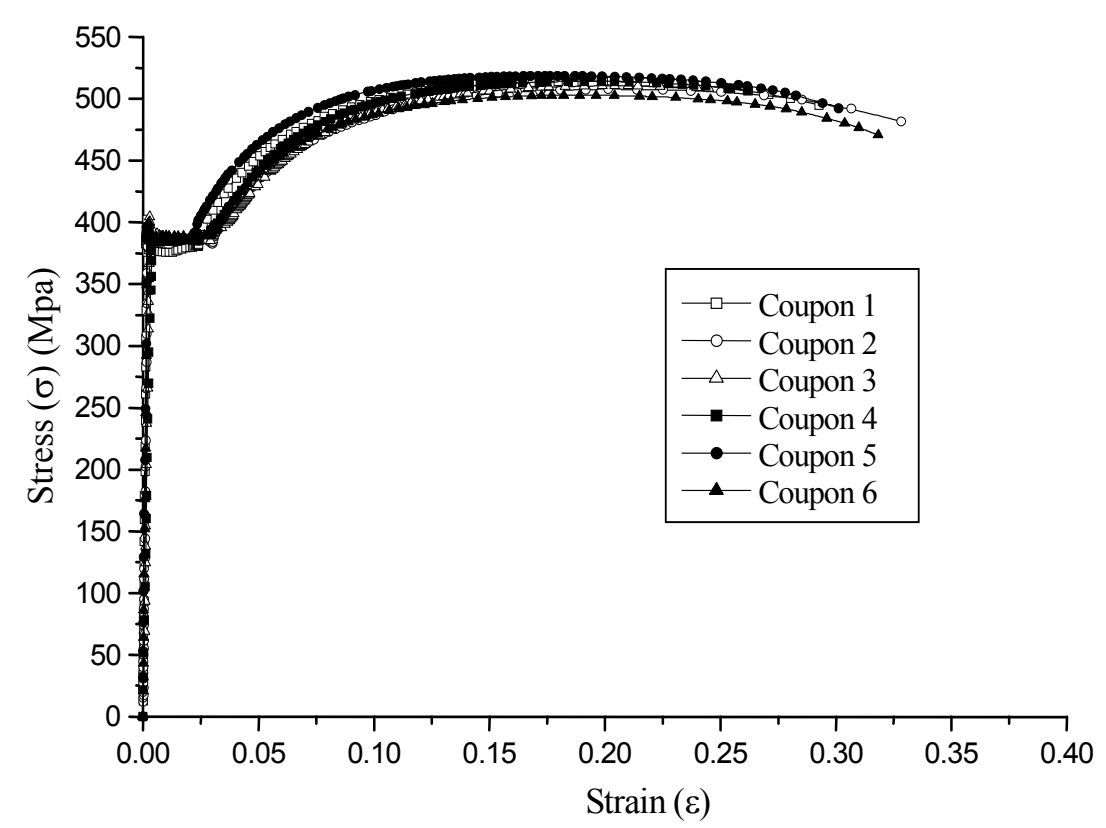

Figure 15. The Coupon Tests Results

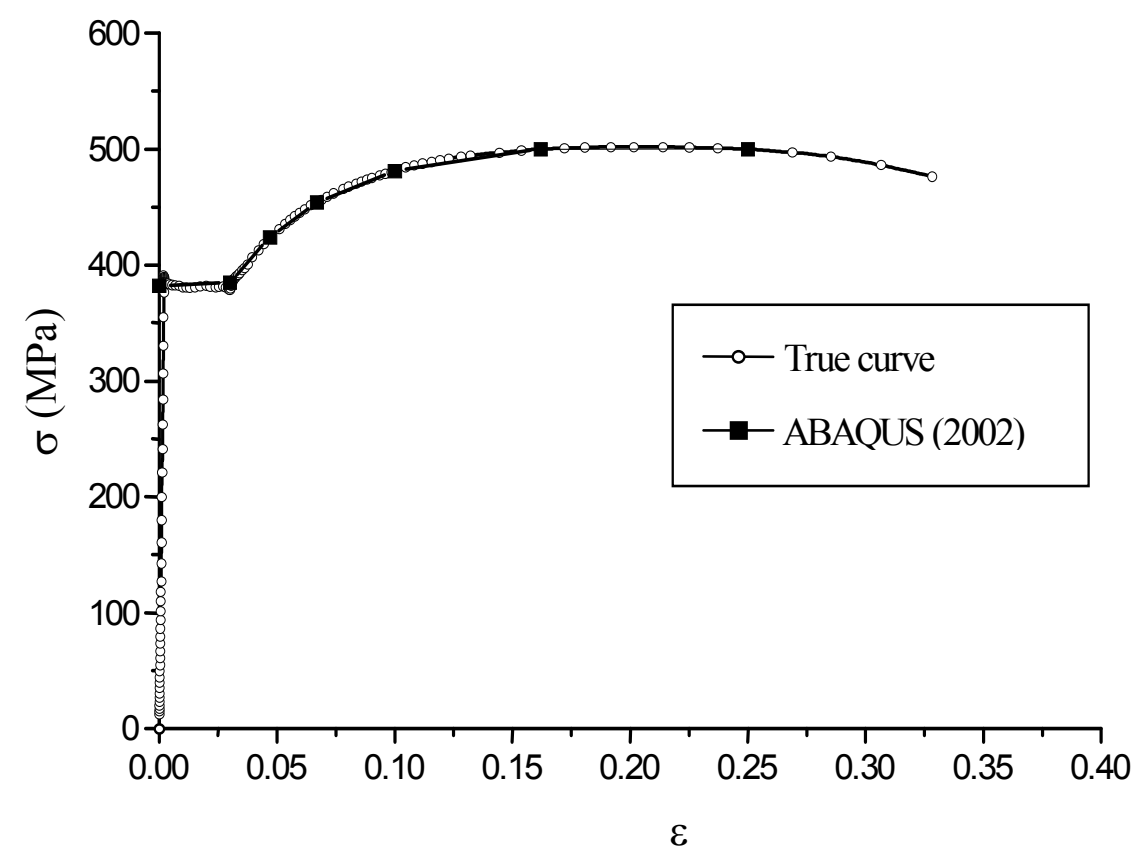

Figure 16. The Stress-strain Curve used in the Numerical Analyses

The load-displacement curves and the crack mouth opening displacements (CMOD) are calculated and compared with the experimental recordings as shown in Figs. 17 and 18. It can be found that a good agreement between the numerical and experimental results is obtained up to the failure. Therefore, it is reasonable to use the proposed numerical model to analyze the cracked SHS T-joints. 


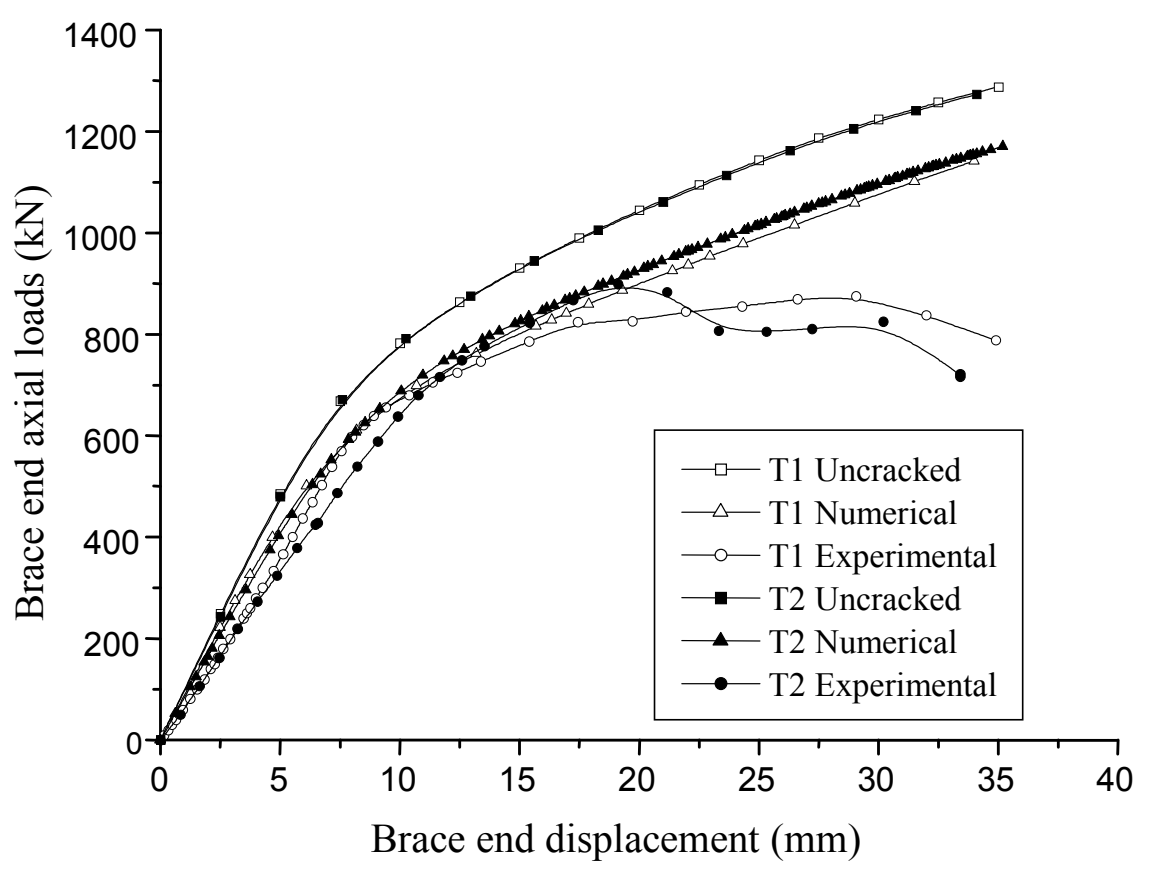

Figure 17. The Load-displacement Curves

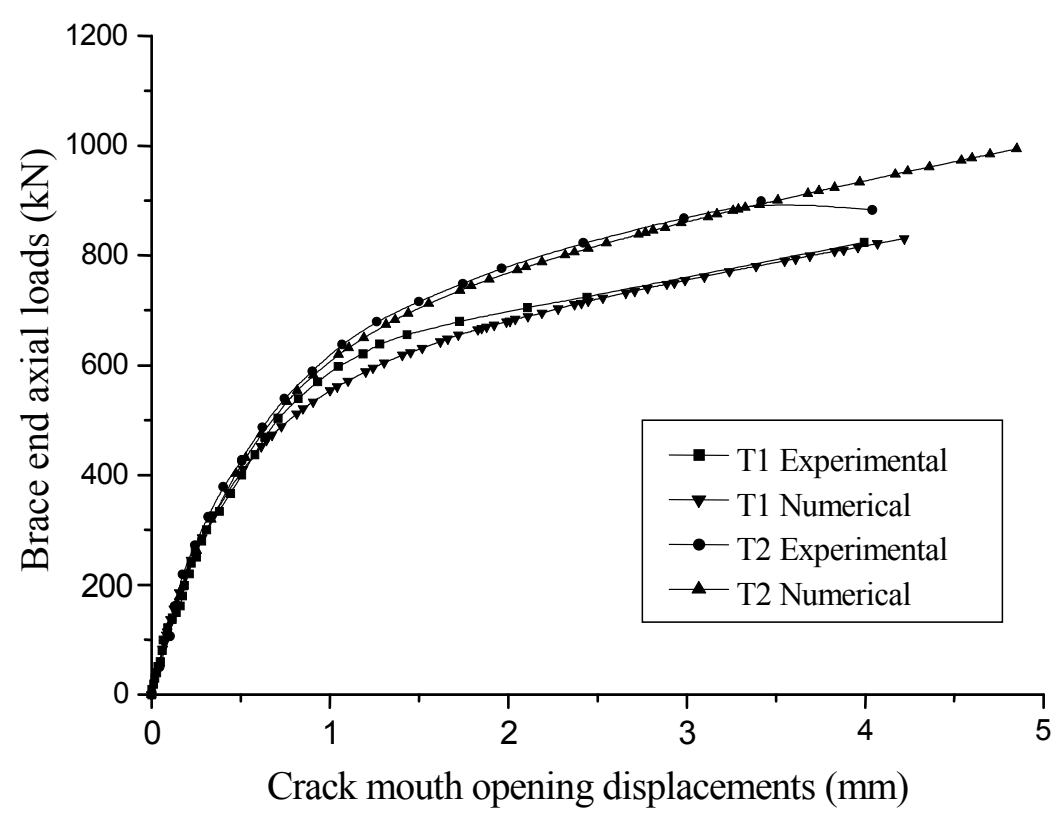

Figure 18. The Load-CMOD Curves at the Deepest Point

\section{NUMERICAL CASE STUDIES}

Based on the proposed numerical model, several sets of numerical cases which have different geometrical parameters and crack sizes are studied. The dimensions and crack sizes of the SHS T-joints are tabulated in Table 3. The material parameters are the same as the experimental specimens. The tension load is applied at the end of the brace under displacement control, and the two ends of the chord are pinned and connect to the ground as shown in Fig. 19. In accordance with the twice elastic compliance criterion (Cheaitani and Burdekin [6]), the plastic collapse loads of the 
cracked joints are calculated and tabulated in Table 4. It can be found that the difference between the numerical results and the plastic collapse loads calculated from the Equation (6) is small. In practice, the influence of the weld width and the chord wall thickness are neglected when Equation (6) is used. Therefore, the brace to chord width ratio $\beta$ is equal to $\frac{b_{1}}{b_{0}}$, and the brace height to chord width ratio $\eta$ is equal to $\frac{h_{1}}{b_{0}}$. The plastic collapse loads $P_{\mathrm{u}}^{\prime}$, which neglect the weld and the chord wall thickness, are also calculated and tabulated in Table 4. It can be seen that the plastic collapse loads $P_{\mathrm{u}}^{\prime}$ gives a very conservative results, and the difference between the $P_{\mathrm{u}}^{\prime}$ and numerical plastic collapse load increases with increasing $\beta$ ratio.

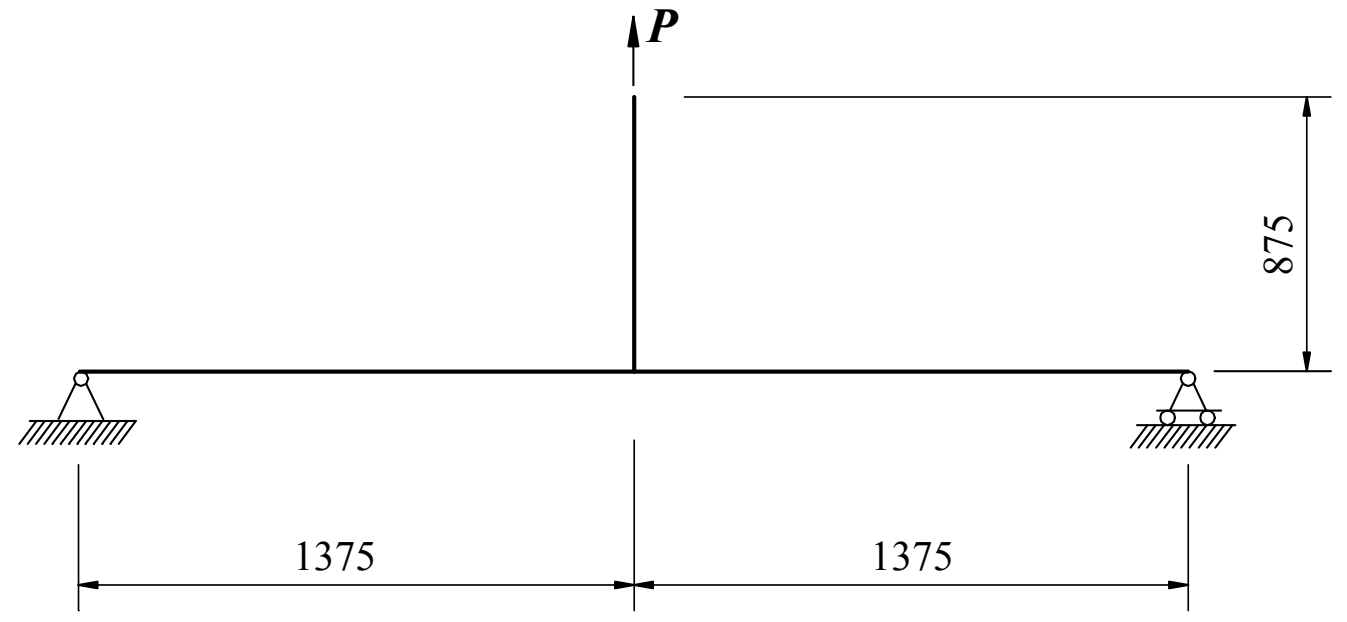

Figure 19. The Load and Boundary Conditions

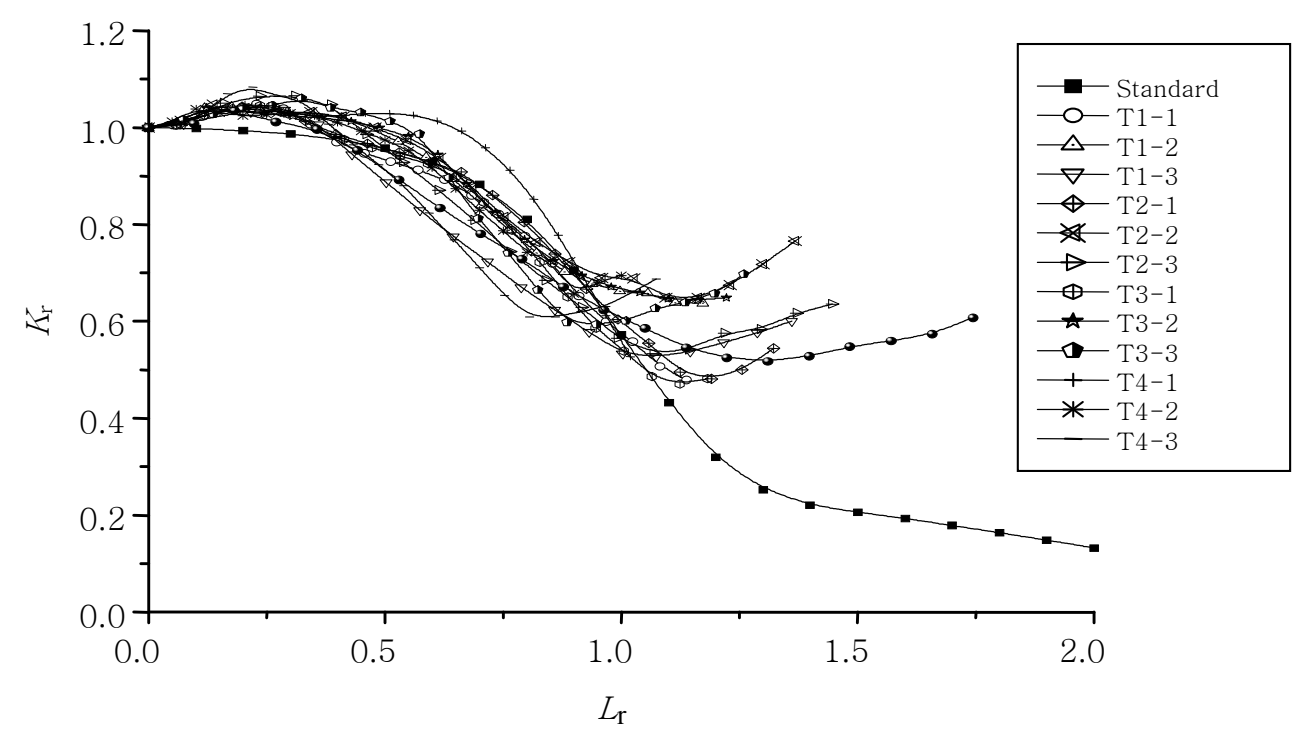

Figure 20. The Failure Assessment Curves for the SHS T-joints $\left(L_{\mathrm{r}}=\right.$ Applied Load/Numerical Collapse Load $)$ 
Table 3. The Dimensions and Crack Sizes of the SHS T-joints with Cracks

\begin{tabular}{|c|c|c|c|c|c|c|c|c|c|}
\hline $\begin{array}{c}\text { Serie } \\
\mathrm{s}\end{array}$ & $\begin{array}{c}b_{0} \\
(\mathrm{~mm})\end{array}$ & $\begin{array}{c}b_{1} \\
(\mathrm{~mm})\end{array}$ & $\begin{array}{c}t_{0} \\
(\mathrm{~mm})\end{array}$ & $\begin{array}{c}t_{\mathrm{w}} \\
(\mathrm{mm})\end{array}$ & No. & $a / t_{0}$ & $\begin{array}{c}l_{\mathrm{c} 1} \\
(\mathrm{~mm})\end{array}$ & $\begin{array}{c}l_{\mathrm{c} 2} \\
(\mathrm{~mm})\end{array}$ & $\begin{array}{c}\text { Inclined } \\
\text { angle } \theta\end{array}$ \\
\hline \multirow[t]{3}{*}{$\mathrm{T} 1$} & \multirow[t]{3}{*}{350} & \multirow[t]{3}{*}{150} & \multirow[t]{3}{*}{16} & \multirow[t]{3}{*}{8} & 1 & 0.4 & 33 & 83 & $30^{\circ}$ \\
\hline & & & & & 2 & 0.6 & 43 & 108 & $45^{\circ}$ \\
\hline & & & & & 3 & 0.8 & 63 & 158 & $45^{\circ}$ \\
\hline \multirow[t]{3}{*}{ T2 } & \multirow[t]{3}{*}{350} & \multirow[t]{3}{*}{200} & \multirow[t]{3}{*}{15} & \multirow[t]{3}{*}{8} & 1 & 0.4 & 38 & 108 & $30^{\circ}$ \\
\hline & & & & & 2 & 0.6 & 58 & 128 & $45^{\circ}$ \\
\hline & & & & & 3 & 0.8 & 68 & 178 & $45^{\circ}$ \\
\hline \multirow[t]{3}{*}{ T3 } & \multirow[t]{3}{*}{350} & \multirow[t]{3}{*}{200} & \multirow[t]{3}{*}{15} & \multirow[t]{3}{*}{12} & 1 & 0.4 & 42 & 102 & $30^{\circ}$ \\
\hline & & & & & 2 & 0.6 & 62 & 132 & $45^{\circ}$ \\
\hline & & & & & 3 & 0.8 & 72 & 182 & $45^{\circ}$ \\
\hline \multirow[t]{3}{*}{ T4 } & \multirow[t]{3}{*}{350} & \multirow[t]{3}{*}{250} & \multirow[t]{3}{*}{16} & \multirow[t]{3}{*}{8} & 1 & 0.4 & 63 & 203 & $30^{\circ}$ \\
\hline & & & & & 2 & 0.6 & 73 & 223 & $45^{\circ}$ \\
\hline & & & & & 3 & 0.8 & 93 & 243 & $45^{\circ}$ \\
\hline
\end{tabular}

Table 4. The Plastic Collapse Loads of the SHS T-joints

\begin{tabular}{|c|c|c|c|c|c|c|}
\hline Series & No. & $\begin{array}{c}\text { Numerical } \\
(\mathrm{kN})\end{array}$ & $\begin{array}{c}P_{\mathrm{u}} \\
(\mathrm{kN})\end{array}$ & Difference & $\begin{array}{c}P_{\mathrm{u}}^{\prime} \\
(\mathrm{kN})\end{array}$ & Difference \\
\hline \multirow{3}{*}{$\mathrm{T} 1$} & 1 & 784.8 & 753.6 & $3.9 \%$ & 646.1 & $17.7 \%$ \\
\cline { 2 - 7 } & 2 & 762.8 & 738.3 & $3.2 \%$ & 634.8 & $16.7 \%$ \\
\cline { 2 - 7 } & 3 & 732.3 & 713.4 & $2.6 \%$ & 615.9 & $15.9 \%$ \\
\hline \multirow{3}{*}{$\mathrm{T} 2$} & 1 & 975.1 & 921.0 & $5.5 \%$ & 728.6 & $25.3 \%$ \\
\cline { 2 - 7 } & 2 & 942.6 & 899.4 & $4.6 \%$ & 713.8 & $24.3 \%$ \\
\cline { 2 - 7 } & 3 & 897.4 & 869.5 & $3.1 \%$ & 693.2 & $22.8 \%$ \\
\hline \multirow{3}{*}{$\mathrm{T} 3$} & 1 & 1091.1 & 987.8 & $0.9 \%$ & 730.4 & $33.1 \%$ \\
\cline { 2 - 7 } & 2 & 1050.3 & 961.3 & $0.8 \%$ & 713.8 & $32.0 \%$ \\
\cline { 2 - 7 } T4 & 3 & 1005.4 & 928.7 & $7.6 \%$ & 693.1 & $31.1 \%$ \\
\cline { 2 - 7 } & 2 & 1947.1 & 1820.7 & $6.5 \%$ & 1144.5 & $41.2 \%$ \\
\cline { 2 - 7 } & 3 & 1785.6 & 1759.1 & $1.5 \%$ & 1112.3 & $37.7 \%$ \\
\hline
\end{tabular}

The failure assessment curves for the numerical cases are generated using the $J$-integral approach. Fig. 20 shows the assessment curves constructed by using the numerical plastic collapse load as the plastic collapse load of the joints. The standard FAD curve is the BS7910 [5] Level 3A curve. It can be seen that most of the assessment curves in Fig. 20 fall inside the standard curve. Therefore the use of the standard curve is unsafe. If the standard curve is adopted to assess the strength of the cracked SHS T-joints, a conservative plastic collapse load or a safety factor should be used. As mentioned earlier, the plastic collapse load $P_{u}^{\prime}$ which neglects the influence of the weld and the chord wall thickness gives a conservative results, therefore, the failure assessment curves which adopt $P_{\mathrm{u}}^{\prime}$ as the plastic collapse load to calculate the $L_{\mathrm{r}}$ are constructed and shown in Fig. 21. It can be seen that all of the curves fall outside or close to the standard curve. Hence, the use of the standard BS7910 [5] Level 3A curve for the assessment of the cracked SHS T-joint is safe. 


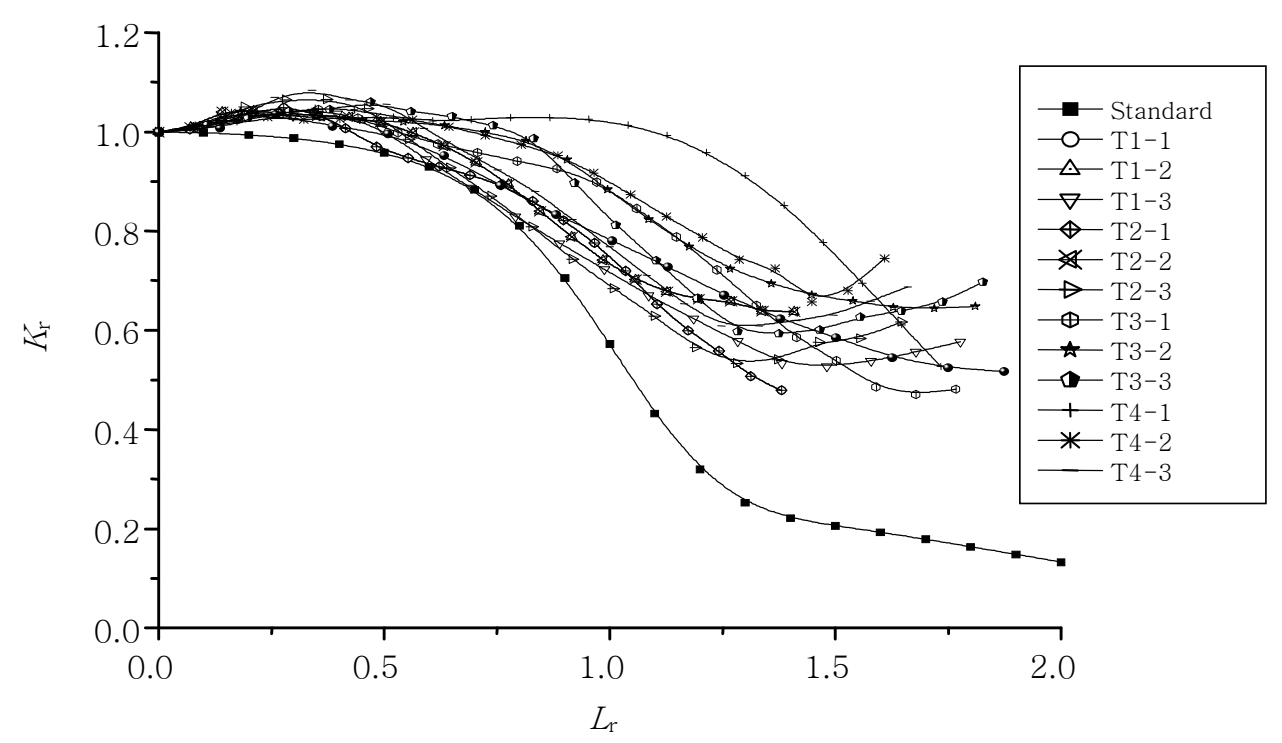

Figure 21. The Failure Assessment Curves for the SHS T-joints

$$
\left(L_{\mathrm{r}}=\text { Applied } \operatorname{Load} / P_{\mathrm{u}}^{\prime}\right)
$$

Using the BS7910 [5] Level 3A FAD, the fatigue-cracked specimens of T1 and T2 are assessed as shown in Fig. 22, and the calculation of the parameters $K_{\mathrm{r}}$ and $L_{\mathrm{r}}$ are tabulated in Table 5. The fracture toughness of BS 4360-50D steel were given by Hancock and Spurrier [10]. The plane strain fracture toughness $\delta_{\text {IC }}$ is about $2.7 \mathrm{~mm}$ on the upper shelf. The values of CTOD are derived from the experiments. It can be seen that the critical failure loads which are predicted from the failure assessment diagram are lower than the true failure loads which are recorded from the experimental tests. Therefore, the use of the standard assessment curve is safe for SHS T-joints under brace end axial loads.

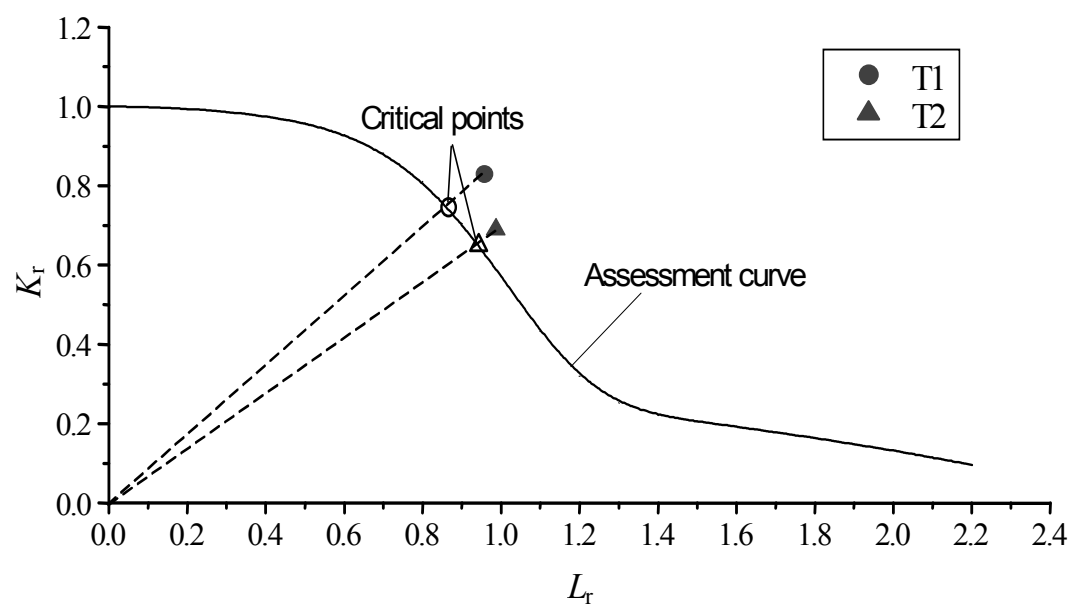

Figure 22. Failure Assessment of BS7910 (1999) Level 3A for the Specimens

Table 5. The Parameters of $K_{\mathrm{r}}$ and $L_{\mathrm{r}}$

\begin{tabular}{|c|c|c|c|c|c|c|}
\hline Specimens & $\begin{array}{c}\delta_{\mathrm{IC}} \\
(\mathrm{mm})\end{array}$ & $\begin{array}{c}\delta_{\mathrm{CTOD}} \\
(\mathrm{mm})\end{array}$ & $K_{\mathrm{r}}$ & $\begin{array}{c}\text { Failure load } \\
(\mathrm{kN})\end{array}$ & $\begin{array}{c}P_{\mathrm{u}}^{\prime} \\
(\mathrm{kN})\end{array}$ & $L_{\mathrm{r}}$ \\
\hline $\mathrm{T} 1$ & 2.7 & 1.86 & 0.83 & 824.0 & 866.3 & 0.95 \\
\hline $\mathrm{T} 2$ & 2.7 & 1.29 & 0.69 & 899.0 & 928.1 & 0.97 \\
\hline
\end{tabular}




\section{CONCLUSIONS}

In accordance with the yield line theory, the plastic collapse load of the cracked SHS T-joints under brace end axial loads is derived. This plastic collapse load is then validated by numerical models and experimental tests. Based on this plastic collapse load, the failure assessment diagrams (FADs) of this type of joints are constructed using the $J$-integral approach. Elastic and elastic-plastic finite element analyses have been carried out on various geometries of cracked SHS T-joints under brace end axial loads. These models contain at least one surface crack under the weld toe, and cover the following geometrical ranges of $\beta=0.43,0.57$ and 0.71 . It is found that the use of standard BS7910 (1999) Level 3A FAD is safe if the plastic collapse load is calculated using Equation (6) neglecting the influence of weld and chord wall thickness. The two full-scale specimens are then assessed, and it is concluded that the standard FAD gives a safe assessment.

\section{Nomenclature}

$\begin{array}{lll}a & = & \text { vertical crack depth } \\ d_{0} & = & \text { chord width } \\ d_{1} & = & \text { brace width } \\ K & = & \text { stress intensity factor } \\ K_{\mathrm{r}} & = & \text { fracture ratio using stress intensity factor } \\ l_{\mathrm{c} 1} & = & \text { crack length along the weld toe parallel to the chord side wall } \\ l_{\mathrm{c} 2} & = & \text { crack length along the weld toe perpendicular to the chord side wall } \\ L_{\mathrm{r}} & = & \text { ratio of applied load to plastic collapse load } \\ P & = & \text { applied load } \\ P_{\mathrm{u}} & = & \text { plastic collapse load considering the influence of welds } \\ P_{\mathrm{u}}^{\prime} & = & \text { plastic collapse load neglecting the influence of welds } \\ t_{0} & = & \text { chord wall thickness } \\ t_{1} & = & \text { brace wall thickness } \\ t_{w} & = & \text { weld width } \\ \beta & = & \text { brace to chord width ratio } \\ \eta & = & \text { brace height to chord width ratio } \\ \gamma & = & \text { rotation angle of crack face } \\ \delta_{\mathrm{c}} & = & \text { critical crack tip opening displacement } \\ \delta_{\mathrm{CMOD}} & = & \text { crack mouth opening displacement (CMOD) } \\ \delta, \quad \delta_{\text {Сто口 }} & =\text { crack tip opening displacement (CTOD) } \\ \delta_{\mathrm{r}} & =\quad \text { fracture ratio using CTOD parameters } \\ \sigma_{\mathrm{e} 0} & =\text { yield stress of material } \\ \theta & =\text { crack inclined angle }\end{array}$




\section{REFERENCES}

[1] ABAQUS, "Theory Manual”, Version 6.4, Hobbit, Karlsson \& Sorensen Inc., USA, 2002.

[2] Aliabadi, M.H. and Rooke, D.P., "Numerical Fracture Mechanics", Kluwer Academic Publishers, Dordrecht, The Netherlands, 1991.

[3] American Welding Society (AWS), "ANSI/AWS D1.1: 2000 Structural Welding Code Steel", Miami, USA, 2002.

[4] API RP579, "Fitness-for-Service", American Petroleum Institute, Washington, USA, 2000.

[5] BS7910, "Guide to Methods for Assessing the Acceptability of Flaws in Metallic Structures", British Standards Institution, London, UK, 2005.

[6] Cheaitani, M.J. and Burdekin, F.M., "Ultimate Strength of Cracked Tubular Joints, Tubular Structures VI", Melbourne, Australia, A.A. Balkema-Rotterdam, 1994, pp. 607-616.

[7] Chiew, S.P., Lie, S.T., Lee, C.K. and Ji, H.L., "Stress Analysis of Square-to-square Tubular T-joint under Combined Loads", 7th International Conference on Steel \& Space Structures, Singapore, 2002, pp. 199-206.

[8] Dover, W.D., Dharmavasan, S., Brennan, F.P. and Marsh, K.J., "Fatigue Crack Growth in Offshore Structures". Engineering Materials Advisory Services Ltd, Chameleon Press, London, UK, 1995.

[9] Dowling, A.B. and Townley, C.H.A., "The Effect of Defect on Structural Failure: A Two-criteria Approach, International Journal of Pressure Vessels and Piping, 1975, Vol. 3, No. 2, pp. 77-107.

[10] Hancock, P. and Spurrier, J., "The Influence of Stored Energy on the Interpretation of Fracture Test Results", Proceedings of International Conference, Fracture Toughness Testing-Methods, Interpretation and Application, The Welding Institute (TWI), Abington, Cambridge UK, 1982, Vol. 1, Paper 37.

[11] Lapidus, L. and Pinder, G.F., "Numerical Solution of Partial Differential Equations in Science and Engineering”, John Wiley and Sons Inc., New York, USA, 1982.

[12] Packer, J.A., Wardenier, J., Kurobane, Y., Dutta, D. and Yeomans, N., "Design Guide for Rectangular Hollow Section (RHS) Joints under Predominantly Static Loading”, CIDECT 3, TÜV-Verlag GmbH, Köln, Germany, 1992.

[13] R6, "Assessment of the Integrity of Structures containing Defects", Revision 4, British Energy, Gloucester, UK, 2001.

[14] Wardenier, J., "Hollow Section Joints", Delft University Press, Delft University of Technology, Delft, The Netherlands, 1982. 